In: Nutrition and Agricultural

Development. Significance and Potential for

the Tropics. N.S. Scrimshaw \& M. Bghar (

editors). Plenum Press, N.Y. p 45-60, 1976.

5

\title{
The Environment of the Malnourished Child
}

\author{
Leonardo J. Mate \\ Institute de Investisecion en Selud \\ University of Costa-Rice \\ Costa Rica
}

Patterns of interdependence between man and his environment have differed over time. Man first began to intervene in his environment by organized hunting for food and later he began to domesticate animals and plants. Sedentary societies grew with time, decimating wildlife, destroying or endangering primary forests, and inducing significant soil erosion. Metal craftmanship, the development of complex methods of warfare, and growth of industry and sophisticated technology have led to modern patterns of life in advanced societies. Some of these patterns are now being questioned because, through exploitation of the environment, man is compromising his own survival.

Most of the world's population has lagged behind this process of social evolution, and still subsists on traditional agriculture, -using rudimentary technology. Such populations are controlled by governments based in urban areas that enjoy a greater degree of development and hold most of the wealth and political power.

\section{THE ENVIRONMENT OF THE MALNOURISHED MAN}

Figure 1 illustrates the present status of the world in relation to famine. Bangladesh, India, and parts of equatorial Africa and of Brazil are experiencing a severe food shortage. Other regions of Africa, Asia, and Latin America face prospective famines. The figure, however, was not intended to illustrate the present food crisis but to point out that the affected areas are in the tropics and subtropics, where environmental forces act more strongly and negatively on man, to decrease and often frustrate the effectiveness of his efforts. 


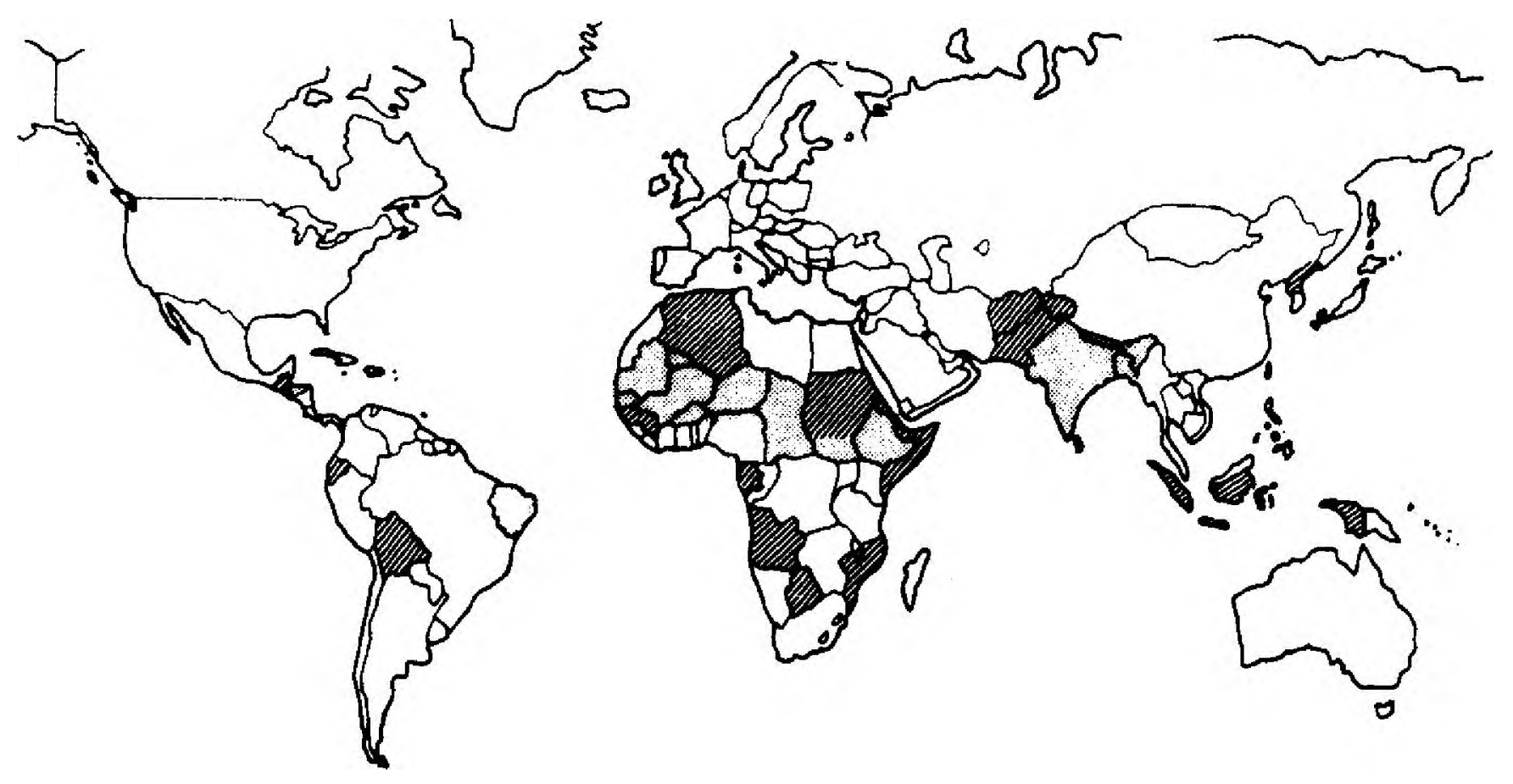

FIG. 1. World map, 1974, showing areas of famine (shaded) and of potential famine (lines). 
Environmental factors can be classified as physical, biological, and social, with a realization that they are closely interdependent and often inseparable from each other. The physical environment includes soil, water, and air. The biological environment includes the viruses, bacteria, and parasites, many of which cause disease and death in man or in the plants and animals on which he depends. The social environment comprises socioeconomic characteristics that result from societal evolution of traditions, beliefs, and forms of social organization.

\section{THE PHYSICAL ENVIRONMENT}

In the tropics and subtropics, compared to temperate zones, man is at some disadvantage. In the tropics, steady high temperatures, humidity, rainfall or drought, erosion, and occasional natural disasters are considered deterrents to progress. Such environments diminish the working capacity and creativity of unprotected man (1). They pose greater demands on human body water and electrolytes, and may be a source of nitrogen loss (10). More importantly, tropical environments favor the vectors of blood and tissue parasites and maintenance of the cycles of hookworm, trematodes, and jungle virus infections. In many areas the climate promotes growth of weeds, insects, and fungi detrimental to food crops.

In the tropics Amerindian civilizations remained at a low level of technological development. The arriving Europeans succeeded in improving yields of cash crops and moved some people from subsistence agriculture to large land holdings. The resulting profound changes in social and family life cannot be denied, nor their effects on the economy, health, and welfare of society (14). The important consideration is that populations still living on subsistence agriculture are characteristically poor. Poverty favors deficient sanitation and poor diets, leading to a high incidence of nutritional and infectious disease, and death.

\section{THE BIOLOGICAL ENVIRONMENT}

Man living in the tropics is also at greater risk of developing endemic infectious diseases. Some of these infections may affect the human being from gestation onward. The results presented here were derived from long-term prospective observations in a typical village of Guatemala (7,9). A high incidence of infectious disease was recorded among pregnant women in this village: 27 of 100 pregnancies were complicated by bacteriologically confirmed urinary tract infection, an affliction associated with premature birth and low-birth-weight infants (Table I). Furthermore, diarrhea and dysentery appeared in 36 of 100 pregnancies, and lower respiratory disease was present in $30 \%$ of the pregnant 
Table I. Incidence of Infectious Diseases in 82 Women Observed Prospectively during Pregnancy, Santa Maria Cauqué, 1972-1973

\begin{tabular}{|c|c|c|c|c|}
\hline & Respiratory infection & Diarrhea and & $\begin{array}{l}\text { Urinary tract bacterial } \\
\text { infection }\end{array}$ & \\
\hline upper & lower & dysentery & $\left(>10^{5} / \mathrm{m} 1\right)$ & Other illnesses' \\
\hline $\begin{array}{l}\text { Incidence per } 100 \\
\text { pregnancies }\end{array}$ & $104(127 \%) 25(30 \%)$ & $29(36 \%)$ & $22(27 \%)$ & $20(25 \%)$ \\
\hline
\end{tabular}

${ }^{\mathrm{a} C}$ Conjunctivitis, otitis media, stomatitis, skin infection.

females. Deterioration of maternal nutrition during pregnancy because of infection must also affect the developing embryo (15).

Under these circumstances the fetus has greater opportunity to become exposed to infectious agents, or to antigenic components or immunoglobulins synthesized by the mother in the course of her disease. The study of femoral vein blood collected from infants within three to four days after birth revealed $15 \%$ of consecutive newborns from four lowland Guatemalan villages with elevated $1 \mathrm{gM}$ levels $(0.19$ $\mathrm{mg} / \mathrm{ml}$ ) (Table 11), an incidence in excess of occurrence in industrial societies (5). The high rates of elevated $1 \mathrm{gM}$ values have not yet been explained, but presumably some of these represent congenital infection. In a preliminary study in one Indian village, $1 \%$ of the infants were congenitally infected with cytomegalovirus and $1.3 \%$ with Toxoplasma, while $1.3 \%$ were shedding echoviruses at birth (9). The possible consequence of increased risk of fetal antigenic stimulation and congenital infection deserves scrutiny. Intra-

Table II. Incidence of Neonates with High

Concentrations of Inununoglobulin

M (1gM), Four Guatemalan Ladino Villages, 1972-1973

\begin{tabular}{ccc}
\hline Village number & Number of infants & $\begin{array}{l}\text { Number (and \%) } \\
\text { with 1gM }>0.20 \\
\mathrm{mg} / \mathrm{ml}\end{array}$ \\
\hline 1 & 48 & $10(21)$ \\
2 & 52 & $4(8)$ \\
3 & 40 & $6(15)$ \\
4 & 67 & $11(16)$ \\
Total & 207 & $31(15)$ \\
\hline
\end{tabular}

\&Elevated values in cord serum confirmed in blood from infant's femoral vein. IgAtl was measured by radial immunodiffusion. Data of the Divisions of Environmental Biology and Human Development, INCAP. 
uterine infection is known to induce fetal wastage, embryopathy, premature birth, low birth weight, and postnatal sequelae.

The small size of child-bearing women in poor rural areas, their poor nutritional status resulting from deficient diets and frequent episodes of infectious disease, and the presence of fetal antigenic stimulation are factors that help to explain the $7 \%$ rate of premature birth and the $32 \%$ incidence of fetal growth retardation. By itself, poor fetal growth diminishes survival and retards growth of children (10). Childbirth in rural areas throughout the world offers many opportunities for contamination of the child with maternal feces, an event made more significant by the high rates of maternal infection. More than $8 \%$ of five- and seven-day-old neonates were found to be excreting enteroviruses. Early infection with Shigella and protozoa also occurs, but is less frequent (9). These infections, however, generally are asymptomatic and short-lived and disappear in days or a few weeks. The rural neonate has a remarkable resistance to infection attributable to the adequate nutrition and resistance factors provided by breast milk. The situation changes when weaning begins, at two to five months of age, because supplemental foods are easily contaminated by polluted water or by the mother herself as she prepares them.

Milk output in women who do not supplement their own diets diminishes by the second or third month. Weaning is protracted, extending into the second year of life in most cases, and this coincides with the occurrence of weanling diarrhea, a syndrome caused by a variety of infectious agents and a deteriorated nutritional status. The combined effect of inadequate food intakes and frequent exposure to infectious agents results in a succession of infections, each episode further depleting the child. The magnitude of infection correlates directly with the onset of clinical manifestations.

Particularly high rates of diarrhea! diseases and respiratory illnesses are observed (Figure 2). It should be recognized that children are continuously being infected and that clinical manifestations occur virtually in a continuum, as Figure 3 illustrates. Children may be ill for as long as a third of their first year of life. These data correspond to a typical highland region devoid of hookworm and of diseases transmitted by snails and arthropods. In many lowland areas, malaria, flukes, and arboviruses enlarge the morbidity spectrum.

The impact of infection on health is evident in a severe case of whooping cough ( Figure 4). The child exhibited pronounced weight loss consequent to anorexia and vomiting and metabolic alterations; the nutritional status deteriorated seriously, favoring clinical manifestations of other infectious agents (9). Recovery of the preillness weight did not occur until 40 weeks later. The arrest in growth of this child at such an early age probably resulted in impairment of biological functions. The nutritional status even in well-nourished individuals deteriorates in the presence of any infectious disease and the effects are of still 


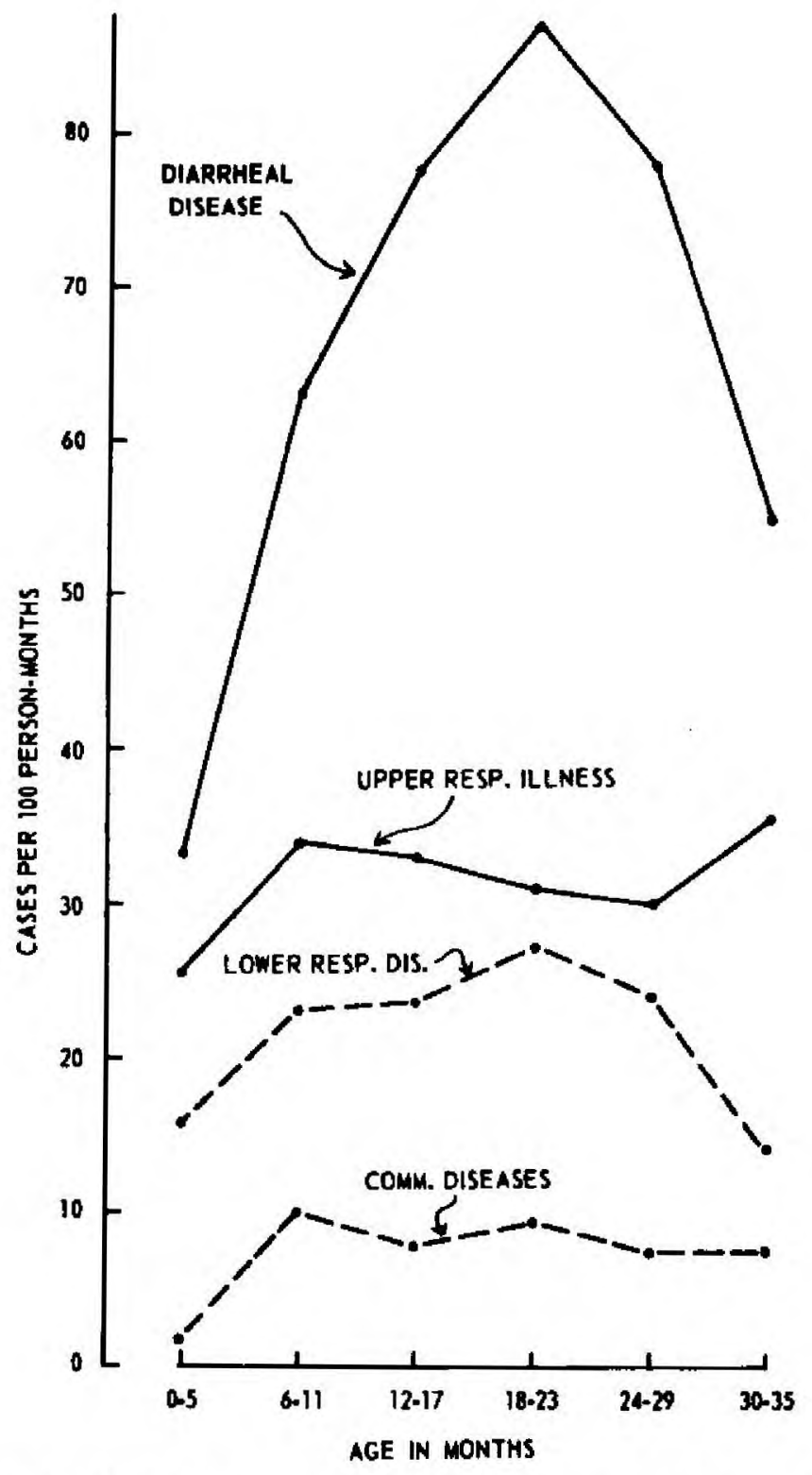

FIG. 2. Rates of infectious diseases, as cases per 100 person-months, in a cohort of 45 children observed from birth to age 3 years. Reappearance of symptoms after 24 hours identified a new case. Santa Marla Cauqué, 1964-1971. 
greater consequence to infants and young children, particularly if they are already malnourished.

In less developed societies, the response to an infectious process in the child is often withdrawal of solid food and sometimes the giving of strong purgatives.

Infections commonly are accompanied by anorexia, vomiting, increased peristalsis, and systemic manifestations, often resulting in marked reduction of food intake, impaired digestion and absorption, and nutrient depletion (11). Other alterations are loss of tissue-particularly epithelium, blood, muscle, and liverdepending on the type of infection, its localization and pathogenesis. In both intestinal and systemic diseases there is increased loss of nitrogen, amino acids, electrolytes, and vitamins. Adults experiencing severe infectious disease show impaired performance or inability to work at all (2). However, even subclinical or "silent" infections induce stress responses with increased nitrogen excretion in urine (3).

The metabolic alterations associated with infection have been classed as nutrient overutilization, nutrient sequestration, and nutrient diversion. In over-utilization there is increased expenditure of glycogen, mobilization of amino acids from skeletal muscle for gluconeogenesis in the liver, increased synthesis of lipids, and overutilization of vitamins. Sequestration of iron in the liver occurs even in the presence of adequate stores of hemosiderin, a phenomenon apparently mediated by a protein factor released by phagocytes. This perhaps contributes to the anemia in children experiencing recurring infections, even when they live in hookworm-free areas and where dietary iron is only mildly deficient or even adequate. Nutrient diversion includes an uptake of plasma amino acids for abnormal synthesis of haptoglobin, tryptophan-oxygenase, tyroxin-transaminase, and other enzymes. Also, the body diverts its biosynthetic pathways to produce the protein, lipids, and carbohydrates needed for viral replication. Thus, by a variety of mechanisms, the high frequency of infections in developing societies contributes in an indirect way to the food shortage observed in developing regions of the world.

On the other hand, malnutrition, whether primary or secondary to interaction with infection, affects the host's immune capacity, an important issue when one considers that a large proportion of the world's population suffers from varying degrees of malnutrition and is concomitantly exposed to far greater risks of infection than well-nourished populations are (16). Present knowledge indicates that the immunoglobulin system is not affected in persons with mild to moderate forms of malnutrition. However, antibody synthesis is impaired in children with moderate to severe forms of protein-calorie malnutrition (PCM), as evidenced by a failure to elicit a B-cell response with viral and bacterial antigens in untreated kwashiorkor patients.

Alterations in T-cell function and in the amplification of the immune response occur in malnourished persons. In moderate and severe forms of PCM 


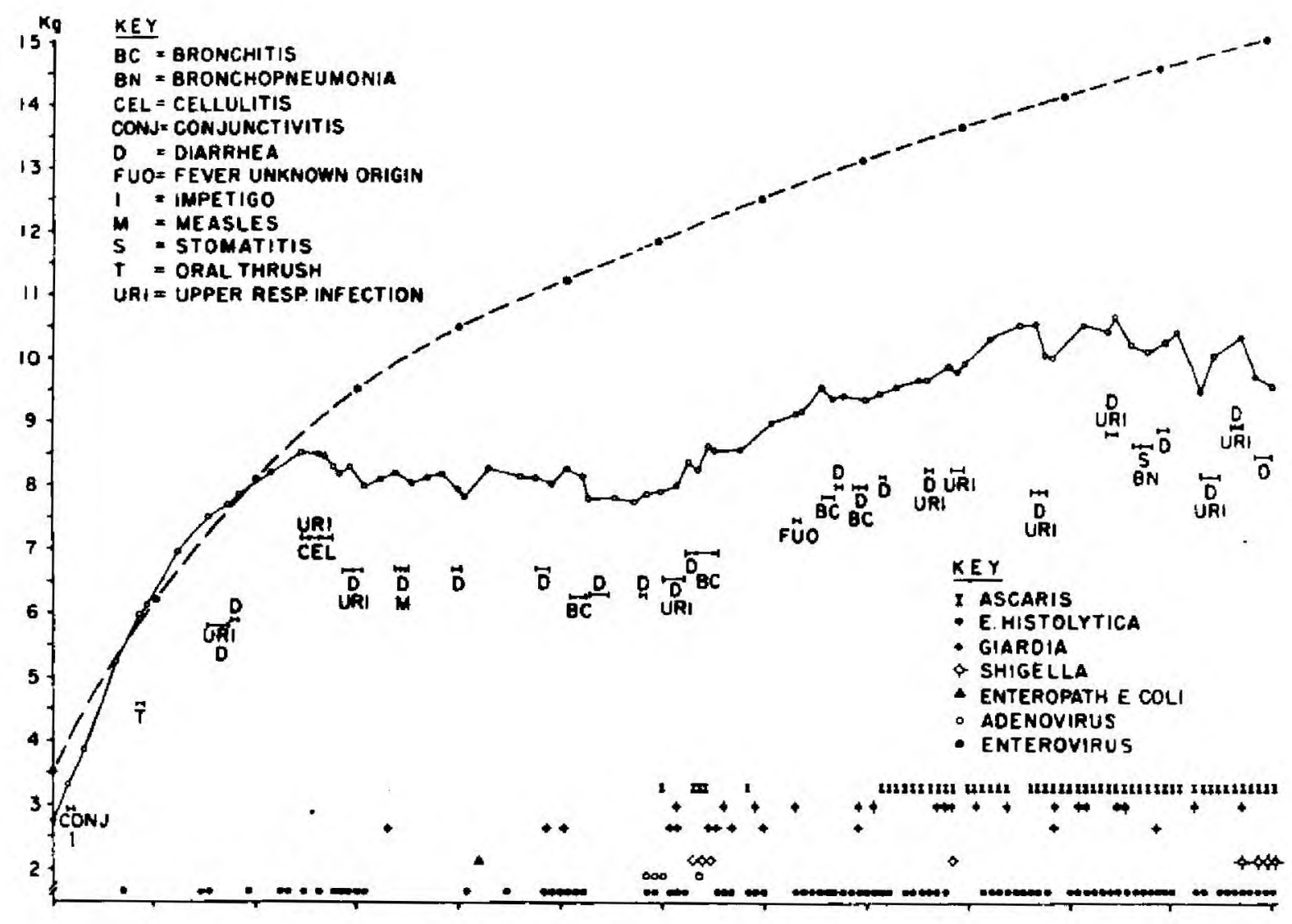




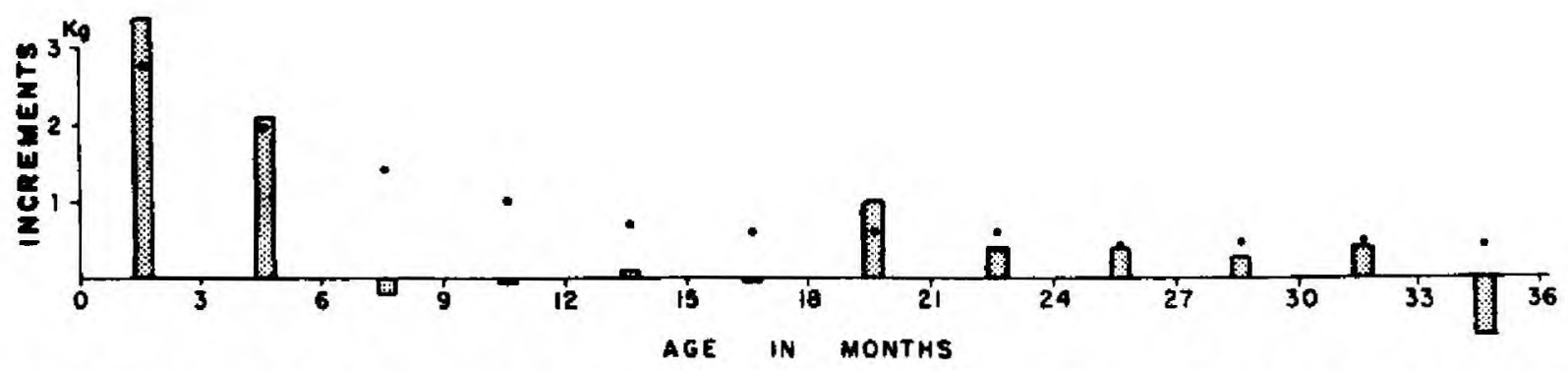

FIG. 3. Weight, infections, and infectious diseases, male child no. 12, Santa Marla Cauque. Top: Solid line represents weight of child; broken line is median of the standard. Length of each horizontal line indicates duration of infectious disease. Each mark shows a week positive for the particular infectious agent. Bottom: Observed weight increments (vertical bars) and expected median increments (dots) of the standard (Mata et al., 1971, reference 8). 


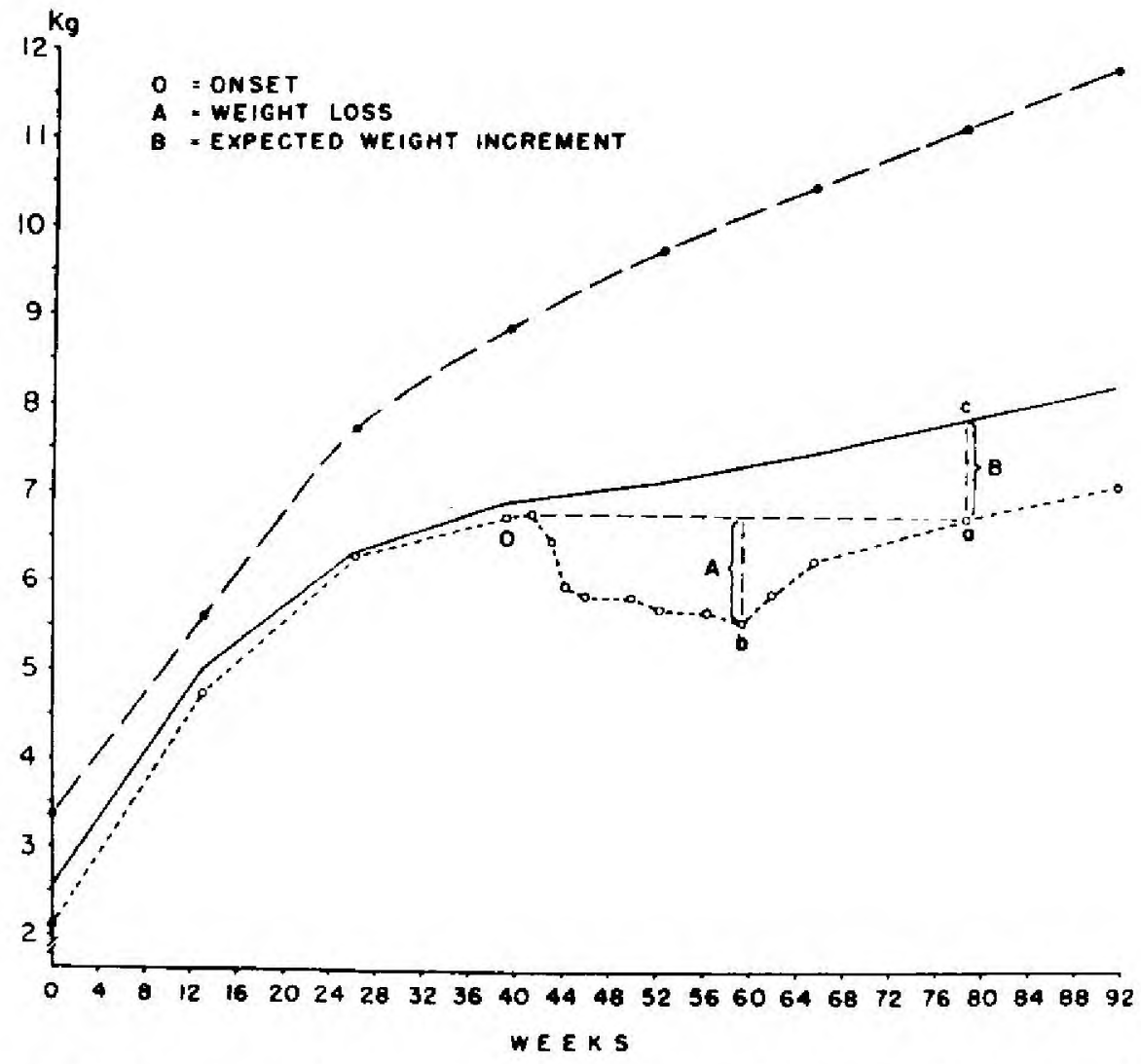

FIG. 4. Whooping cough in a girl of Santa Marla Cauque to illustrate deterioration of nutritional status. Adapted from Mata et al., 1972, reference 9).

there is a decrease in the number of immune cells in liver, bone marrow, spleen, Peyer's patches, and lymph nodes; this could explain the failure of malnourished children to mount a leukocyte response to bacterial infection. Alterations in phagocytic cells result in a diminished capacity to ingest and kill bacteria, a phenomenon apparently related more to lack of iron than to protein depletion. It has already been mentioned that iron sequestration occurs during infection.

Furthermore, malnourished individuals have altered or delayed hypersensitivity reactions. Other manifestations of altered cell-mediated immunity in malnutrition are a depressed capacity for blast transformation after challenge with mitogens, a diminished rosette formation, and alterations in factors important for the amplification of the immune response. These are evident, not only 
in acute PCM, but in underweight children who have experienced fetal growth retardation or early nutritional deprivation (4).

There is no doubt that infection and infectious disease are important factors in determining the occurrence of malnutrition. Conversely, malnutrition diminishes the host's capacity to resist and become immune to infection. The synergistic malnutrition-infection interaction can be considered the most important phenomenon in the genesis of recurring disease, impaired function, and death.

\section{THE SOCIAL ENVIRONMENT}

The frequent interactions between infection and malnutrition in the tropics are related to traditions, low educational level, and socioeconomic underdevelopment, as well as to the characteristics of the physical environment. As long as such deficiencies are not corrected, infection and malnutrition will continue to occur at the present rate or even become worse.

To illustrate, Figure 5 shows illiteracy rates in the six Central American countries, showing that in four of them about half or more of the people cannot read or write (12). It is not surprising that in most rural villages of Central America there is little or no knowledge of how disease is transmitted, of the need to boil drinking water, or how to prepare adequate, hygienic food for weaning infants.

Table III summarizes certain characteristics of a typical community in the Guatemalan highlands, pointing out deficiencies in housing, availability of water, and unsanitary disposal of human wastes-all factors related to transmission of infection.

Furthermore, in the same village, a study made 12 years ago showed that land averaged 10 cuerdas ( 3.3 acres) per family of five members, an amount

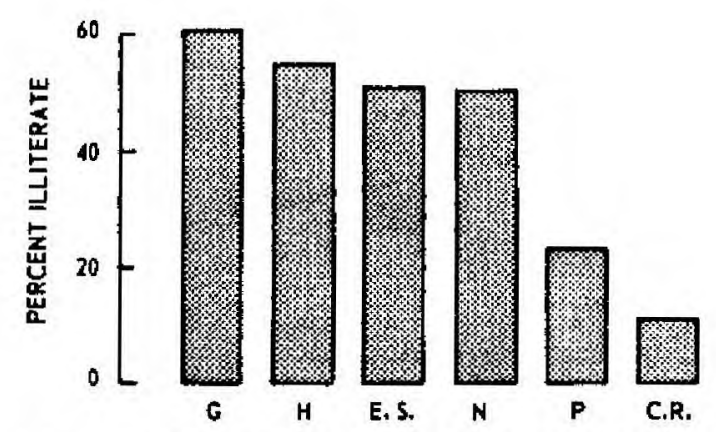

FIG. 5. Miteracy rates, six Republics of Central America, population census of 1960 , SIECA, 1973 (reference 12). (G) Guatemala, (H) Honduras, (E.S.) El Salvador, (N) Nicaragua, (P) Panamá, (C.R.) Costa Rica. 


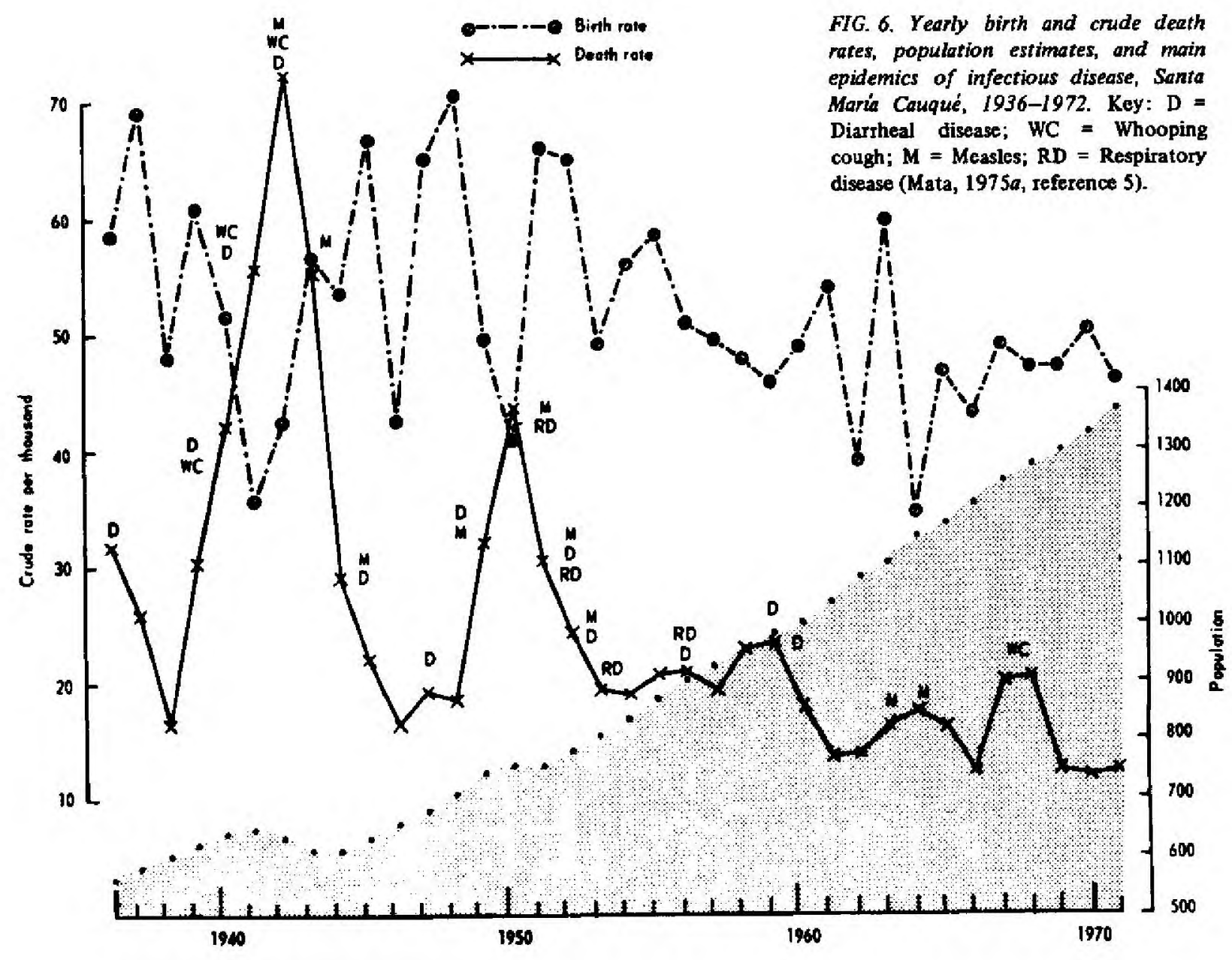


Table III. Characteristics of a Typical

Highland Village of Guatemala, Santa Maria Cauaque, 1967

\begin{tabular}{lc}
\hline \multicolumn{1}{c}{ Features } & Percent homes \\
\hline Earthen floor & $\mathbf{8 6 . 5}$ \\
Piped water & 7.4 \\
Hearth on floor & $\mathbf{8 8 . 7}$ \\
Electricity & 30.3 \\
Privy & 68.0 \\
\hline
\end{tabular}

permitting cultivation of maize and beans to feed the village for one year. Within a decade the land was subdivided further and many young men in the community are now without land, creating a system of servitude not quite existing a few years ago. In addition, individual men and whole families have migrated to urban centers to live in shantytowns and slums, often under worse conditions than those of the village.

At present, the most pressing problem is the saturation of the carrying capacity of the land. Figure 6 shows that after 1950, deaths primarily due to epidemic diseases declined while birth rates remained high (6). In this village and in Guatemala as a whole the population is growing at a rate greater than $3 \%$ per year, without any apparent tendency to decline. Table IV illustrates the present population and population density in Central America and the expectations for the year 2000, figures that speak for themselves.

The economic capacity of villagers is very low, due to population growth, low educational level, primitive methods of agriculture, lack of skill in craftman-

Table IV. Population and Population Density, Central America and Panama ${ }^{\circ}$

\begin{tabular}{|c|c|c|c|c|c|c|c|}
\hline Year & Guatemala & El Salvador & Honduras & Nicaragua & Costa Riea & Panama & Iotal $^{b}$ \\
\hline \multicolumn{8}{|c|}{ Population in millions } \\
\hline 1974 & 5.9 & 3.9 & 2.9 & 2.3 & 1.9 & 1.5 & 18.4 \\
\hline 2000 & 15.7 & 9.6 & 8.0 & 5.7 & 4.4 & 3.7 & 47.1 \\
\hline \multicolumn{8}{|c|}{ Inhabitants per km' } \\
\hline 1974 & 55 & 186 & 26 & 18 & 38 & 20 & 34 \\
\hline 2000 & 145 & 457 & 71 & 34 & 88 & 49 & 94 \\
\hline
\end{tabular}

aSIECA, 1973 (reference 12).

${ }^{b}$ For Central America and Panama. 
Table V. Mean Gross Domestic Product, U.S. Dollars per Caput, Selected Regions of Guatemalaa

\begin{tabular}{lcrc}
\hline \multicolumn{1}{c}{ Region } & $1951-1952$ & $1965-1966$ & \% change in 15 years \\
\hline Dept. Guatemala!' & 847 & 1071 & +26 \\
Dept. Sacatepequez & 197 & 123 & -38 \\
All Guatemala, except three depts. & 144 & 104 & -28 \\
Rural Guatemala & 142 & 105 & -26 \\
All Guatemala & 265 & 329 & +24 \\
\hline
\end{tabular}

aAdapted from Smith, 1973 (reference 13).

${ }^{b}$ Mostly Guatemala City.

ship, and little or no village industry or other types of economic development to employ landless people. The impoverishment of the population is evident in the steady decrease in gross domestic product noted for most of rural Guatemala, even before the recent onset of inflation. The country as a whole shows a gain in the gross domestic product, clearly concentrated in Guatemala City (Table V).

\section{SUMMARY}

The study of the relation of man to his environment in developing countries emphasizes the inevitable need for societies to recognize the true causes of infection, malnutrition, and poverty. The need is for improvement in the quality of human life in less developed nations, a recommendation easy to prescribe but difficult to accomplish. Although our pool of knowledge is incomplete, it is adequate to suggest ways to diminish infection, increase food production, utilize food more efficiently, improve education, and provide systems of justice to protect the classes most in need.

The physical environment in tropical and subtropical regions, and the socioeconomic characteristics of the population inhabiting such regions, favor maintenance and transmission of a variety of viruses, bacteria, and parasites that make agricultural progress and social development difficult, and that contribute to poor fetal growth, nutrient wastage, and deficient postnatal physical growth, accounting for most of the childhood morbidity and mortality. In this regard, infections contribute indirectly to the overall food problem in a similar fashion as pests do in terms of food losses and spoilage. The overall effect could be comparable or greater than that resulting from an inadequate capacity to produce or to purchase the food needed.

Thus, my objective has been to stress, within the whole environment, the importance of infection and the need to diminish it. Ways to control and prevent infection are readily known. They have to do with education of the population 
to improve personal and environmental hygiene. Economic investment is necessary to improve housing and water supply systems, waste disposal, and such preventive measures as immunization programs. Although such measures may appear expensive when first implemented, they have long-lasting effects and many require minimal expenditure once they are established. Large segments of the population stand to benefit, and other development interventions can then be introduced. However, these measures should not be implemented singly. They should be accompanied by community development, family planning, social legislation-in other words, the holistic approach to health and welfare. To do otherwise may aggravate the problem by stimulating demographic growth, perpetuating malnutrition and infection, and maintaining underdevelopment.

\section{REFERENCES}

1. Astrand, P. 0., and Rodahl, K., 1970, Textbook of work physiology, McGrawHill, York, pp. 517,523-524.

2. Alluisi, E. A. Beisel, W. R., BarteLloni, P. J., and Coates, G. D., 1973, Behavioral effects of tularemia and sandfly fever in man, J. Infect. Dis. 128: 710717.

3. Beisel, W. R., 1972, Interrelated changes in host metabolism during generalized infectious illness, Am. J. Clin. Nutr. 25: 1254-1260.

4. Chandra, R. K., 1974, Immunocompetence in tow-birth-weight infants after intrauterine malnutrition, Lancet 2: 1393-1394.

5. Mata, L. 3., 1975a, Malnutrition-infection interactions in the tropics, Am. J. Trop. Med. Hyg., 24: 564-574.

6. Mata, L. J., 1975b, The children of Santa Maria Cauque, Cornell/M.I.T. International Nutrition Policy Series, in press.

7. Mata, L. J., Urrutia, J. J., and Garcia, B., 1967, Effect of infection and diet on child growth: Experience in a Guatemalan village, in: Nutrition and infection, $\mathrm{G}$. E. W. Wolstenholme and C. M. O'Connor (eds.), Ciba Foundation Study Group No. 31, Little Brown, Boston, pp. 112-126.

8. Mata, L. J., Urrutia, J. J., and Lechtig, A., 1971, Infection and nutrition of children of a low socioeconomic rural community, Am. J. Clin Nutr. 24: 249-259. 9. Mata, L. J., Urrutia, J. J., Caceres, A., and Guzman, M. A., 1972, The biological environment in a Guatemalan rural community, in: Proceedings of the Western Hemisphere Nutrition Congress III, Futura Publishing Co., New York, pp. 257264.

10. Mata, L. J., Urrutia, J. J., Kronmal, R. A., and Joplin, C., 1975, Survival and physical growth in infancy and early childhood, by birth weight and gestational age. Study in a Guatemalan Indian village, Am. J. Dis. Child., 129: 561-566.

11. Scrimshaw, N. S., Taylor, C. E., and Gordon, J. E., 1968, Interactions of nutrition and infection, World Health Organization Monograph Series No. 57, Geneva, 329 pp.

12. SIECA, 1973, Estadisticas sociales, SIECA, Guatemala, 88 pp.

13. Smith, G. H., 1972, Income and nutrition in the Guatemalan highlands, A dissertation, Department of Economics and the Graduate School of the University of Oregon, University Microfilms, Ann Arbor, Michigan, xiv + 183 pp. 
15. Urrutia. J. J., Mate, L. J., Trent, F., Cruz, J. R., Villatoro, E., and Alexander, R. E., 1975, Infection and low birth weight in a developing country. A study in an Indian village of Guatemala, Am. J. Dis. Child. 129: 558-561.

16. World Health Organization, 1972, A survey of nutritional-immunological interactions, Bull. W. IL 0. 46: 537-546.

\section{COMMENTS}

Carl E. Taylor - Department of International Health, School of Hygiene and Public Health, The Johns Hopkins University, Baltimore, Maryland.

Mata, in his excellent review of the environmental factors influencing malnutrition, concentrated on physical and biological factors. To complement his comments, I will focus on that part of the social environment that relates to social organization and the administration of nutrition and health care.

My major theme is that there is not only a synergism between malnutrition and infections, but an even more practical and important synergism between programs for nutrition and programs for infection control. Our research in India has clearly demonstrated this relationship. There is another program synergism about which we still have a great deal to learn: the relationships between family planning and both nutrition and health programs.

These relationships seem reasonable, and they make common sense to those prepared to believe in them. They are not readily accepted by proponents of categorical or single-approach programs. Specialists trained in one discipline tend to look for solutions in their area of competence. To nutrition specialists, it seemed reasonable to accept that part of the causal synergism suggesting that a nutrition program would limit the severity of infections in addition to improving nutritional status. Similarly, specialists in various means of infection control were able to reinforce their claims for programs such as immunization with the further justification that this would help to prevent malnutrition. Family planning specialists can correctly make the claim that one of the most effective measures for improving maternal and child health and nutrition is to ensure each family's right to have the number of children they can properly care for, with planned spacing of births.

While all of the claims are supported by considerable evidence, there are two serious limitations to their practical relevance:

First, our understanding of how these interactions work in normal populations is so incomplete that we know little about the dynamics or the strengths of particular associations. The relationships are bound together in multiple causation. Most of our measurements are in terms of one-way associations between specific causal factors. For practical program planning and development, we need a new approach to measurement that will provide for parallel quantifica- 
tion of the relative strengths of multiple relationships. When we know the comparative balance among the various associations, we will be able to make a beginning with the cost/effectiveness and benefit/cost judgments that lie at the heart of effective planning.

Second, practical program planning for long-term development is moving away from categorical approaches employing single measures. While mass programs using a single, simple procedure may be extremely productive as initial control measures, they will almost inevitably have to be integrated into a general service for the following reasons:

a. Separately organized categorical programs are usually inefficient in that they involve duplication of logistic requirements, such as travel time of field personnel.

b. They are often less effective than integrated services.

c. Finally, categorical services do not make sense to the people being served. They prefer to get a wider range of care from a worker they have learned to trust than single services from a series of workers divided according to disciplinary distinctions they cannot understand. The objective is to use activities for which there is high spontaneous demand in order to get a change in living patterns relating to needs not yet felt. In most countries, too, the integrated programs have much greater political acceptability.

I turn now to some data from our Rural Health Research Center at Narangwal, India, that show program synergism among services for nutrition, maternal and child health, and family planning. This program was developed as a set of service packages that would tit together naturally within the realities of village life. The estimated total cost for the whole package of integrated care, when research costs were deducted, was calculated to be two dollars per person per year.

At the Narangwal Rural Health Research Center in the Indian Punjab, we had parallel projects, studying the "interactions of malnutrition and infection in weaning age children" and the "integration of maternal and child care and family planning." Groups of villages received the different inputs of specified service packages. In each case routines were evolved that were carried out by a family health worker who had weekly supervision by a nurse and by a physician. Easy referral of complicated cases was arranged for those villages where the family health workers were providing primary medical care. All services were based primarily on routine surveillance. For instance, nutritional supplementation depended on early identification of faltering weight curves by systematically weighing all children under three years of age at intervals of one to three months, depending on age. Similarly, antenatal care focused on identifying specified risk categories, which provided a standardized basis for determining whether puerperal care 
the mother should be referred elsewhere for special attention. Home visiting included morbidity surveillance to ensure early treatment. Preventive measures were stressed, including immunizations and health and nutrition education.

The results show the significant benefits achieved by the synergism of combined programs. Mortality rates of children from 11 to 36 months of age were brought down in three years from 24 per 1000 to 10 per 1000 in groups receiving both nutritional care and infection control. The nutrition-only group of villages had a rate of 23 per 1000 . Ten years earlier the equivalent rate in the Khanna Study villages 27 miles away had been 48 per 1000, and it is a safe assumption that this general improvement can be attributed to the socioeconomic development in the Punjab, including the fact that practically every home had acquired a hand pump before the Narangwal project started. Infant mortality rates also went down, although perinatal and neonatal rates did not.

The second major area of demonstrated effect was in anthropometric indices. Both weight and height curves showed clear and consistent effects after nine months. The nutrition-only group weighed only slightly less than the combined care group, and both exceeded the controls by a significant margin. Significant benefits were also observed in related parameters, such as improved hemoglobin levels, and cell-mediated immunity. Analysis of morbidity data has not yet been completed.

The data on the relationship between family planning and the medical and nutritional care of mothers and children are incomplete. Preliminary analysis suggests that family planning practice was greatest in villages where maternal care and family planning were combined, with consistent practice by $45 \%$ of all couples 15-49 years of age, after four years of field work.

It seems clear that long-term enhancement of nutrition, health, and population stability demands the rapid development of basic services reaching out to the village home. It is hard to generate the political will and commitment to implement such programs because continuity is important. The most effective health officials long ago recognized the wisdom of using a serious epidemic to get acceptance of programs that would otherwise be deferred. We now have the challenge of using the worldwide awareness of massive hunger and increasing death rates to get long-term commitment to the continuing effort necessary to develop basic delivery systems for health, population control, and nutritional improvement. In fact, the most dramatic achievement during the Bihar famine in 1966 was not the mass distribution of food, but the long-range famine prevention that evolved from the pattern of work programs run by voluntary agencies where food was used to pay for developmental work. Villagers themselves organized to build ponds for irrigation, to dig wells, to construct roads, and generally to increase the potential for helping themselves. Developing village level services and local competence is the best way of meeting long-range challenges for improving human welfare and nutrition. 
Ian A. McGregor - Laboratory for Tropical Community Studies, National Institute for Medical Research, Mill Hill, London, England.

Mata stressed that physical, biological, and social aspects of the environment can have an important influence in determining nutritional status. I would like to augment his observations, drawing upon experience in tropical Africa, especially The Gambia.

With regard to physical aspects, marked changes may occur in the environment within years as well as between years, and these changes may be associated with profound alterations in rates of survival and growth of young children. It has been suggested (1) that death rates in young children might serve as an index of the nutritional state of a country. In Keneba, a rural village of some 900 inhabitants in The Gambia, we have recorded deaths occurring at all ages since late 1949. A recent analysis of 725 recorded deaths showed that $69 \%$ occurred before the age of 5 years and that at all other ages, except the oldest (> 50 years), group mortality was very much lower. A further analysis, that took account of seasonal change within years, showed that death in early life occurred more frequently in the wet, rainy season than in the dry months of each year. Seventy-one percent of all deaths before the age of 5 years occurred in the wet months, June-November, inclusive. In contrast, only $41 \%$ of deaths at older ages occurred in these months. By the criterion of mortality, therefore, the nutritional state of Keneba children should be particularly poor each wet season.

Data relating to rates of gain in body weight and height have already been reported (2), confirming that growth of young children in Keneba can be remarkably good in the dry months of the year but that in the rains it may cease completely. Weight increments in pounds per quarter year for Keneba children are shown by age and season in Figure 1 (3). Mean rates of gain over the first three months of life at all seasons exceed values for healthy North American children, and are eloquent testimony to the efficiency of breast feeding by the African mother, and to the benefit of the passive immunity conferred by her to her infant against the important endemic infectious diseases, as Mata described. In the second three months of life, growth rates fall below those of American children, but gains are still made in both wet and dry seasons. However, between 6 and 15 months the pattern changes, and although some weight gain in the dry season persists, increments in the wet months are negligible, even negative. At older ages the pattern again changes and, although wet-season gains remain poor, rates in the dry months increase markedly and surpass American values. These seasonassociated changes in rates of gain in body weight, in which negligible gains alternate with rapid and spectacular increases, are a regular and characteristic feature of growth of young children in Keneba. Because physical changes in the environment similar to those that occur in the Keneba area are common throughout a large part of the tropical world, surveys intended to assess the 


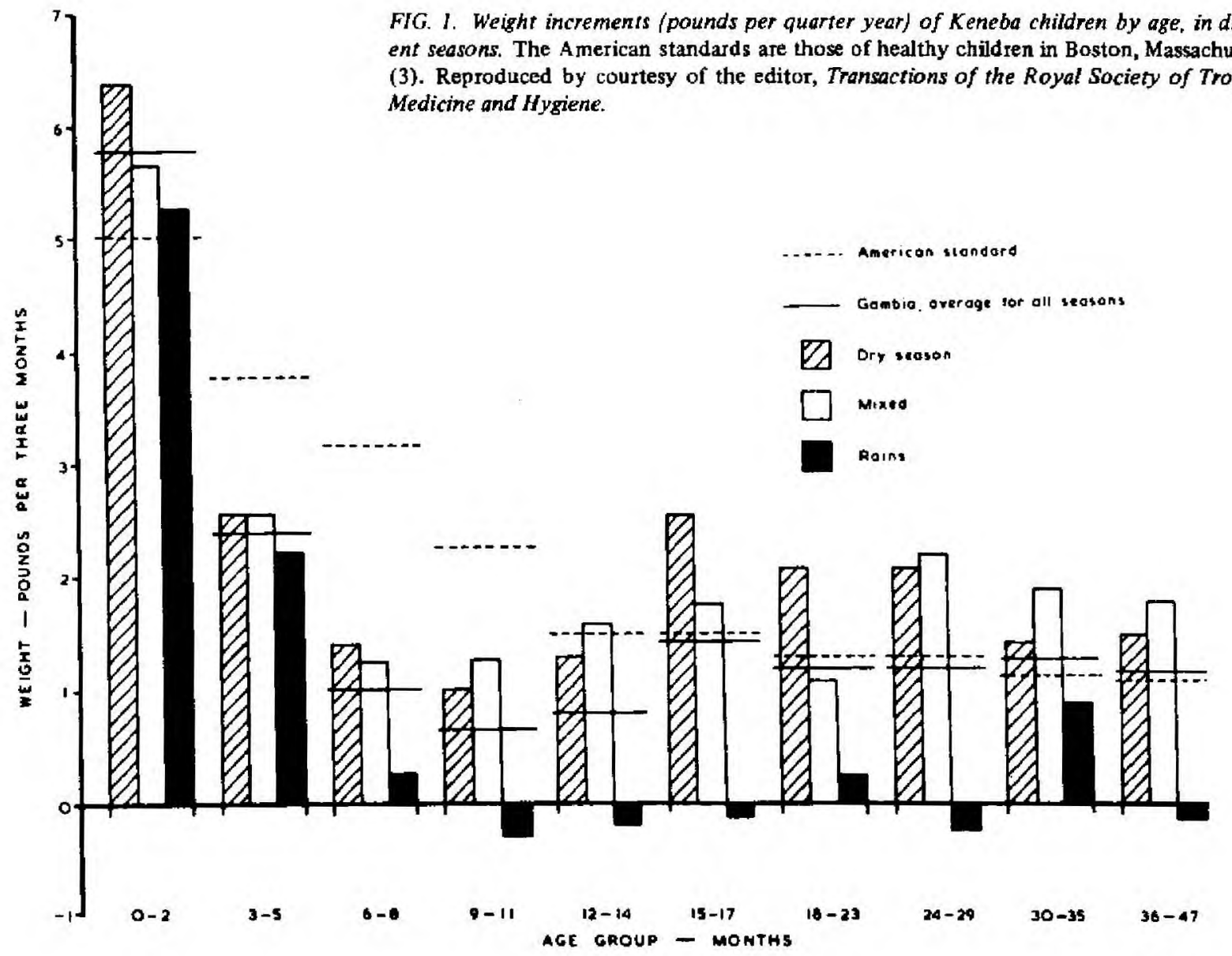

8 Medicine and Hygiene. 
nutritional state of children should be planned to take account of their possible effects.

My colleagues and I share Mata's view that physical, biological, and social changes in the environment often interact to influence nutritional state. This is not the place to analyze in detail the factors we believe combine to cause the season-associated changes I have described. Briefly, however, we have no evidence that growth patterns are disrupted during the rains simply because food is not available. However, the transmission of endemic infections such as malaria, filariasis, intestinal helminthiasis, and insect-borne virus diseases increases dramatically at this time, and clinical illness in the young child becomes frequent and severe over the period when passively acquired immunity has been lost and before acquired immunity has become effective. Concomitant anorexia reduces the intake of a bulky, predominantly vegetarian diet below the level necessary to maintain growth, and this effect is further compounded by a marked lowering of standards of care for young children, imposed by an agricultural economy that demands of the parents long hours of unremitting labor during the relatively short crop-growing season.

In dealing with biological aspects of the environment, Mata outlined how malnutrition may depress the functional efficiency of the different components of man's immune response to infection, thus creating a vicious cycle in which malnutrition enhances infection and infection enhances malnutrition. There is also evidence (4-6) that certain pathogens appear to depress, or even suppress, man's immune response to other infectious agents, although as yet there is little information to indicate how important this mechanism is in increasing host susceptibility to secondary infections, or in worsening nutritional state.

Another subject requiring elucidation is the persistence of effective acquired immunity in environments where malnutrition and infectious disease are frequent companions. Our studies in The Gambia (7) show that in adult Africans the daily rates of synthesis and catabolism of the serum protein immunoglobulin $G$ ( $\mathrm{IgG}$ ) are nearly seven times greater than those of adult Caucasian residents of the United Kingdom. IgG functions importantly in antibody activity, and it is possible that its unduly rapid breakdown and resynthesis may curtail the duration of antibody-mediated acquired immunity.

Investigations, as yet unpublished, made in The Gambia in collaboration with Dr. G. Schild of the World Influenza Centre, National Institute for Medical Research, London, have revealed that, between 1968 and 1974, several epidemics of Hong Kong influenza occurred in our study area. Two important observations have been made. First, persistence of specific influenza antibodies in the sera of Gambians following the epidemic is much shorter than that observed following similar epidemics in populations of more developed countries of the Western world. Secondly, reinfection with the same serotype of the virus is common among Gambians, but is rare in Western populations. These observa- 
tions prompt the question as to whether the standard schedules that have been advocated for immunization campaigns in the developed countries against prevalent infectious diseases will confer an equally effective persistent immunity when used in countries where malnutrition and a high frequency of infection with many different pathogens are common features of childhood.

Finally, Mata described the importance of the social environment. Experience gained in the campaign sponsored by the World Health Organization to eradicate malaria from the world is relevant. Malaria is, in some respects, a simple disease. It can be diagnosed with great precision. Its various vectors can be easily recognized. Drugs that are highly effective against the blood parasite are available, as are residual insecticides that are effective against the mosquito. Yet the global eradication campaign that proved to be so spectacular in developed countries has met with little success in many developing countries, notably those of tropical Africa. Sometimes failure has been attributed to the acquisition of resistance of parasites to drugs or of vectors to insecticides. More usually, however, factors that could be broadly termed social have been blamed. These have included widespread poverty, ignorance and superstition, lack of cooperation-even open hostility to remedial measures-nomadism and high population mobility, poor lines of communication, inadequate health and education services, and paucity of reliable executive staff. In this experience the lesson to be learned is simply that when remedial measures are planned in any area, be they nutritional or against infectious disease, a full and detailed knowledge of local beliefs, customs, and social organization is an essential prerequisite of success.

\section{References}

1. Wills, V. G., and Waterlow, J. C., 1958, The death-rate in the age group 1-4 years as an index of malnutrition, J. Trop. Pediatr. 3: 167.

2. McGregor, 1. A., Rahman, A. K., Thompson, B., Billewicz, W. Z., and Thomson, A. M., 1968, The growth of young children in a Gambian village, Trans. R. Soc. Trop. Med. Hyg. 62: 341.

3. Nelson, W. E., 1969, Textbook of pediatrics (9th ed.), W. B. Saunders Company, Philadelphia, pp. 42-43.

4_ McGregor,1.A.,andBarr,M.,1962,Antibodyresponsetotetanustoxoid inoculation

in malarious and non-malarious Gambian children, Trans. R. Soc. Trop. Med. Hyg. 56: 364 .

5. Greenwood, B. M., Bradley-Moore, A. M., Palit, A., and Bryceson, A. D. M., 1972, immunosuppression in children with malaria, Lancet 1: 169.

6. Greenwood, B. M., Whittle, H. C., and Molyneux, D. H., 1973. Immunosuppression in Gambian trypanosomtasis, Trans. R. Soc. Trap. Med. Hyg. 67: 846 .

7. Cohen, S., and McGregor, 1. A., 1963, Gamma globulin and acquired immunity to 